\section{Donald R. Ulrich Award 2019}

\author{
Sidney J. L. Ribeiro ${ }^{1}$
}

Published online: 12 March 2020

(c) Springer Science+Business Media, LLC, part of Springer Nature 2020

The Donald R. Ulrich Award recognizes outstanding contributions in sol-gel processes made by young researchers. The Award granted in remembrance of Prof. Dr. Donald R. Ulrich, has been given since 1991 during the International Sol-Gel Conference.

For the 2019 process, the Selection Committee was composed of myself (SJLR, Brazil), Professor Sara Aldabe Bilmes (Argentina), Professor Michel Aegerter (Switzerland), Professor Andrei Jitianu (USA) and Professor Kyiofumi Katagiri (Japan). The Committee received seven submissions of young and distinguished candidates. It must be said that it was a hard task to choose the Awardee due to the high level of all of them.

The main evaluation parameters taken into account were as follows: quality and originality, independence, scientific contribution to the Sol-Gel community, scientific production, recommendation letters and maturity of the applicants.

We have the pleasure to announce that the 2019 Ulrich Award was given to Dr. Marco Faustini.

Dr. Marco Faustini, born in 1983, is presently Assistant Professor at the Laboratoire de Chimie de la Matière Condensée de Paris, Sorbonne University, France. His impressive professional career devoted to Sol-Gel processes started as an undergraduate student in Trento, Italy. After a short period in Finland (Aalto University) and a promising start, he went to Paris and finished his $\mathrm{PhD}$ in 2011 at the Sorbonne University under the supervision of Professor David Grosso. A pos-doc at the Pohang University of Science and Technology (Postech) (Pohang, South Korea) under the supervision of Professor D.P. Kim complemented his formation. In 2012, he obtained the present position at the Sorbonne University where a wellestablished independent research team was set. Funding from different agencies and companies was essential for his high level work. In his application form, very ambitious and exciting goals were described highlighting the vibrant Science spirit always looking at the State of the Art in sol-gel related processes.

Dr. Faustini delivered an Invited Lecture at the 20th International Sol-Gel Conference held in St Petersburg, Russia. This Special Issue is devoted to papers presented at the Conference.

We do hope that this award will encourage young scientists to create new sol-gel routes for developing future tailored functional materials.

On the left, the awardee Marco Faustini and on the right, Masahide Takahashi, president of the ISGS board in 2019

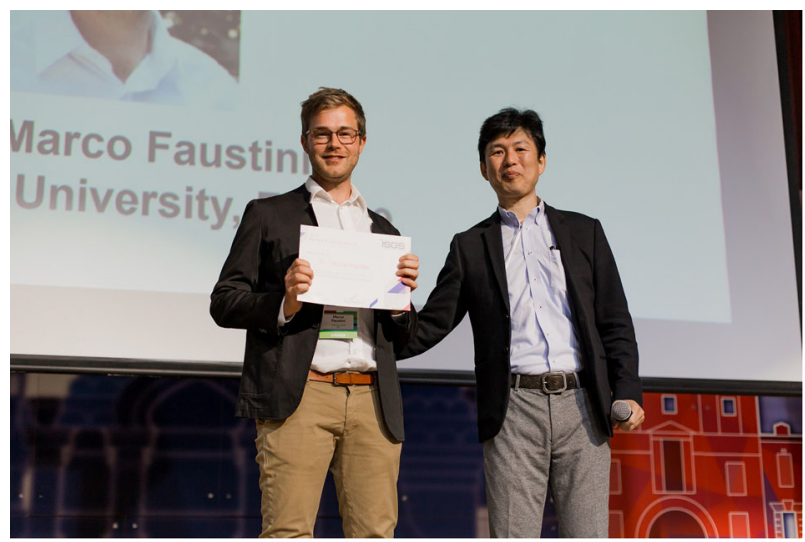

Sidney J. L. Ribeiro

sjlribeiro@gmail.com

1 Institute of Chemistry, São Paulo State University (UNESP), Araraquara, SP 14800-060, Brazil 